\title{
América: fábrica de historiografías $y$ alteridades
}

\section{₹ \\ America: Factory of Historiographies and Otherness}

\author{
Carlos Arturo Hernández Dávila \\ Escuela Nacional de Antropología e Historia \\ México \\ Correo: carlosarturohernandezdavila@gmail.com \\ https://orcid.org/0000-0001-9810-5916 \\ DOI: 10.48I02/hyg.vi56.344
}

Artículo recibido: 4/05/2020

Artículo aceptado: 28/10/2020

\section{ABSTRACT}

From the critical review of the book by Miguel, Segundo Guzmán, Historia y mirada de las crónicas de América, Universidad de Guadalajara (2018), a reflection on american alterity, seen from the office of the historian, is developed.

Key words: Miguel Segundo; Chronicles.

\section{RESUMEN}

A partir de la revisión crítica del libro de Miguel, Segundo Guzmán, Historia y mirada de las crónicas de América, Universidad de Guadalajara (2018), se desarrolla una reflexión sobre la alteridad americana vista desde el oficio del historiador.

Palabras clave: Miguel Segundo; crónicas.

uevamente, América. Como si de un pozo sin fondo se tra-
tara, el lector que se adentre en las más de 400 páginas de la Historia y mirada de las crónicas de América (2018), de Miguel 
Segundo, tendrá la ocasión de revisar las formas en las cuales esta región del mundo, antes de y para ser descrita, definida o interpretada, fue antes concebida como una extensión del pensamiento occidental. Este tema, con fortuna, ha ocupado en las últimas décadas a varios historiadores, cuyo debate mantiene una vigencia incuestionable, y ha encontrado una acogida que no riñe con una saludable crítica. Constituye, además, una larga saga que arranca, por mencionar a algunos, en los textos ya clásicos de Edmundo O' Gorman, ${ }^{1}$ continúa con Guy Rozat ${ }^{2}$ y Alfonso Mendiola ${ }^{3}$ y llega hasta los trabajos de historiadores de generaciones muy recientes, como el presentado también por Óscar Fernando López Meraz $^{4}$ y el del propio Miguel Segundo.

Así las cosas, el debate, por lo que podemos constatar, goza de una indudable vitalidad, la cual saludo desde la orilla de la etnología, una disciplina que en México debería abrevar con más humildad de los trabajos de los colegas historiadores, y asumo la tarea de comentar por una alusión profesional, pues Miguel Ángel Segundo Guzmán parte de la intención de "pensar el pasado como un etnólogo". Esta desiderata exige la elección de un método que en la obra elige el camino de la exotización de Occidente, y exige evitar la simplificación reduccionista, y de ahí que el empeño de Segundo es arriesgado, debido a que, entre el medio centenar de fuentes que su aparto crítico nos ofrece, las que se ocupan del mundo americano son la minoría (tres), y acotadas sólo al mundo novohispano. Ejemplos de esta exotización

\footnotetext{
${ }^{1}$ Una revisión sugerente, puede consultarse en Ainhoa Suárez Gómez, "Historiología: Edmundo O’Gorman, José Ortega y Gasset, y los fundamentos de la ciencia de la historia”.

${ }^{2}$ Un trabajo más reciente en esta línea: Guy Rozat, "Los relatos de la conquista de México como hoyo negro de una memoria esquizofrenizante".

${ }^{3}$ Las referencias a la obra de Mendiola podrían desbordar las páginas de este comentario. Refiero al lector: "El giro historiográfico. La observación de observaciones del pasado".

${ }^{4}$ Óscar Fernando López Meraz, "Memoria, experiencia y cuerpo en crónicas franciscanas del siglo Xvi: la construcción del natural mesoamericano".
} 
de los textos de Occidente no son escasos: los trabajos del antropólogo Roger Bartra sobre el salvaje son un buen ejemplo, ${ }^{5}$ pero viene a mi mente el aporte de Walter Mignolo ${ }^{6}$ sobre el análisis de las crónicas, cartas y relaciones tempranas de la conquista de América, en donde más allá de las tipologías literarias, apuesta por una acuciosa investigación sobre los textos que significan una determinada cultura o un periodo histórico concreto. Con estos antecedentes, sostengo que criticar el libro de Segundo exige revisar a fondo si dicha etnologización es posible con su método.

Dividida en tres partes ("La simbólica de la guerra en Occidente"; "Las tecnologías del cuerpo: antiguos, cristianos y mexicas", y "Fragmentos para una historia de la alteridad en Occidente"), y cada parte organizada por varios capítulos (trece en total), la obra está concebida como una ciudad con trece puertas giratorias que nos llevan a la plaza central donde discurren y se exhiben las diferentes exégesis de la alteridad como artificio. Así, la primera parte parece seguir a Borges en la intuición de que no puede haber guerra en Ilión si no hay un Homero que la cante. Si la guerra genera entre otras cosas la necesidad de loar a los vencedores y exhibir a los vencidos (esto es, de narrar maravillas desde el logos del dominante), podemos estar de acuerdo con el autor en que "En la lógica del relato los prodigios tienen una función central, con ellos se inaugura una historia de victoria, y en esa economía simbólica se eligen los acontecimientos que prefiguran o anuncian la derrota del Otro por parte de un narrador omnisciente, el cual relata el destino de los acontecimientos" (p. 76). No hay relato sin maravilla, sin prodigio que lo insufle.

No es ocioso que en esta primera parte el lector sea invitado a perseguir una genealogía de héroes de un belicismo memorable, convertidos en gloriosos ancestros de la memoria militar de

\footnotetext{
${ }^{5}$ Roger Bartra, El salvaje en el espejo; El salvaje artificial.

${ }^{6}$ Para Walter Mignolo, un texto es "un acto verbal consignado en la memoria colectiva, y de alta significación en la organización de la cultura". Cfr. "Cartas, crónicas y relaciones del descubrimiento y la conquista”, p. 57.
} 
Occidente: es sugerente observar las múltiples conexiones que revelan la traslación de sus hazañas, erigidas en la épica fundante de una saga que en los triunfos de Hernán Cortés ofrece una de sus versiones más sofisticadas, luego de la reconquista de la península ibérica. Los ejércitos señoriales no van, como el Quijote, desfaciendo entuertos. En el caso de la Nueva España Cortés y sus huestes están más cerca de Santiago que de los caballeros andantes y galantes: la invocación del favor del cielo traza una línea insuperable que distribuye en el mundo a los victoriosos por la mano del Dios verdadero, otorgándoles potestad incuestionable sobre los vencidos que se subyugan al orden de aquéllos. Vencidos también están sus inútiles, impávidos e inconmovibles dioses, sean éstos el demonio -Alá, Tezcatilpoca o Wiracocha-. Es la Hispania Victrix la que se encumbra al allegarse de más de dos milenios de tradición para encajar en la memoria del mundo el esplendor de su triunfo. En contraparte, las empresas de la colonización emprendida por ingleses y franceses en América no reivindican para sí ni la simbólica sagrada ni la genealogía heráldica: san Jorge no socorrió a los ingleses en la conquista de sus treces colonias, ni san Martín de Tours fue el aliado celestial de las tropas francesas en la conquista de la Nouvelle France. En Nueva España se discurre por otras vías. Así, Segundo permite comprender la importancia del contexto de enunciación utilizado como tecnología escriturística en las Cartas de Relación de Cortés. Nuestro autor insiste en que "Se debe destruir la presunción de transparencia en el lenguaje conquistador" (p. 93) y para ello recurre, fiel a su intención de etnógrafo de textos, a afirmar que "Es necesario trazar distancia histórica para comprenderlas: es necesario exotizar los imaginarios de esas cartas" (p. 119).

En la segunda parte, Miguel Segundo ofrece su reflexión sobre el cuerpo del indio vencido, quien, luego del cataclismo que devastó su mundo, es leído, interpretado y grafiado de acuerdo con las disposiciones, usos y tecnologías efectuadas sobre su carne. Es ésta y su posición ontológica la que lo define ante los ojos del fun-

372 / Carlos Arturo Hernández Dávila 
cionario de la corona o del evangelizador como pagano, cristiano, hereje, endemoniado, perezoso, laborioso, vicioso, avasallado, irredento o sedicioso. El interés de Segundo no es aún el cuerpo mestizo (que no es ni indio, ni negro, ni español) al que Carmen Bernard describe ya en el siglo xviII como aquel que encarnaba (nunca mejor dicho) los estereotipos de vulgaridad, insolencia, desfachatez e indisciplina casi total. No: en el siglo Xvi el destino de cuerpos y almas se encuentra irremediablemente destinado a una fatal colisión de cosmologías disímiles con fatales consecuencias: la empresa de evangelización dispuso en el mismo plano la conversión profunda del alma y la profilaxis integral y totalitaria del cuerpo, tanto individual como social. Las relecturas propuestas por Miguel Segundo a los textos de Mendieta, Motolinía y Sahagún parecen enfocarse en el mejor estilo de quienes se han dedicado al análisis del trabajo de los evangelizadores franciscanos, desde el deslumbrante trabajo de Louise Burkhart, pasando por el ya clásico de Georges Baudot o el de Viviana Díaz Balsera. Aquí es necesario señalar que si bien es cierto es que López Meraz se ocupa igualmente del análisis, en las crónicas franciscanas de la Nueva España, del cuerpo indígena, evangelizado por los franciscanos del siglo XVI, es de justicia reconocer que la diferencia entre la propuesta de aquél y la de Segundo reside en la escala: éste nos ofrece una reflexión de un calado más amplificado, por tratarse de un trabajo que exigió una revisión mucho más exhaustiva y profunda, incluso a nivel de los contrastes que permitieran comprender la in-corporación indígena al universo cristiano.

Segundo nos demuestra que, así como Cortés construye en sus Cartas de Relación un conjunto de tropos destinados a procurar la verosimilitud suficiente con la cual ponderar sus méritos militares, los religiosos en cambio reescriben (con notoria intencionalidad apologética) y construyen al sujeto-objeto ideal de sus empresas misionales. Se pregunta Segundo: "¿intentan describir al otro o lo quieren evangelizar?, ¿son antropólogos o frailes?, ¿usan informantes o catecúmenos?, ¿escriben etnografía o historia 
cristiana?” (p. 216). Será por esto que mientras registra la polifonía de voces que integran los Huehuetlatolli, Sahagún se ausenta él mismo de la escena, permitiendo que en ese vacío se instale el multiverso de memorias orales trasvasadas a la escritura, y así disponibles para ser interpretadas por medio de la acomodatio efectuada en el pasado indígena, a un tiempo recién devastado y recreado.

Los frailes estaban convencidos de que los remotos antepasados de los indios a quienes ellos convertían "alcanzaron esta noticia de un Dios verdadero", justificando su afirmación no en las palabras dichas por sus informantes, sino en la forma en la cual empleaba la retórica: "esta manera de hablar les quedó de cuando sus muy antiguos antepasados debieron tener natural y particular conocimiento del verdadero Dios, teniendo creencia que había criado el mundo, y era Señor de él y lo gobernaba”. ${ }^{7}$ Entre la edad pretérita y el tiempo que vivían, el demonio había hecho presa de los naturales. Así, se justifica que la retórica de la guerra empleada por Cortés o Díaz del Castillo fabrica la alteridad indígena vencida en lo militar por la gracia de Dios; de la pluma de Sahagún y del resto de frailes-cronistas nació el mito originario de una tierra ancestralmente bautizada por Quetzalcóatl/santo Tomás, pronto sometida a las fuerzas del infierno, y después entregada providencial y proféticamente a sus nuevos protectores espirituales. El mecanismo es de una eficacia irreprochable: no hay franciscanismo utópico sin el indio ávido de redención, así como no hay victoria mirífica del ejército del Dios verdadero sin un conjunto derrotado en tres partes: el indio, sus dioses y su pasado. El autor de esta novísima simbólica es un nuevo Cid Campeador que somete y humilla ídolos y almas ante las soberanas plantas del Dios y del Rey. Segundo remata así su itinerario: "el cristianismo avanzó por los cuerpos, los espiritualizó y domesticó. La memoria india, purificada y cristianizada, adquirió un lugar privilegiado

${ }^{7}$ Fray Jerónimo de Mendieta, Historia eclesiástica indiana, lib ii, cap. viii, p. 196.

374 / Carlos Arturo Hernández Dávila 
en la lógica de la Salvación Universal. Sólo colonizada podía ser rescatada para el Reino de Dios" (p. 246).

La tercera parte del libro se compone de serie de capítulos en los que Segundo nos propone admirar la dispersión panóptica de aquellos modelos que apelaban a la otredad en Occidente durante al menos dos milenios. Este catálogo de alteridades exigía descripciones graduales, y se construye con "restos y sobras" de materiales humanos y no humanos: gigantes y cíclopes, pero también judíos, moros, hunos, godos, germanos, mongoles, sarracenos, herejes, gnósticos y también con los panteones divinos de estos otros más veteranos.

Una vez expuesto el plan general de la obra, revisemos de manera breve sus alcances. El autor nos ofrece en su extensa exposición una arqueología de las culturas occidentales antes, durante y después de su violenta irrupción en América, eligiendo exclusivamente fuentes traducidas al español, lo cual puede ser un riesgo para un etnólogo que observa las observaciones del pasado. Estas tres partes se encuentran ensambladas y cuentan con un efecto desigual. Segundo sabe que uno de los problemas al abordar un asunto del que se pueden construir bibliotecas enteras, es la necesidad de desarrollar un estado del arte que nos permita ubicar desde dónde una nueva voz reclama el derecho de decir algo nuevo. Y sabiéndolo, lo intenta con suficiencia. Mi crítica se abre desde la constatación de reconocer que la investigación sobre la (de)construcción de América ha desbordado el campo de la historia, y ha ocupado en las últimas décadas la atención de intelectuales que provienen de otros campos como la lingüística postestructural (Todorov), los estudios decoloniales (Mignolo) o la etnología desde el llamado "giro ontológico" (entre otros autores, por Eduardo Viveiros de Castro): ${ }^{8}$ ¿será posible dialogar entre

${ }^{8}$ Tzvetan Todorov, La conquista de América. El problema del otro; Mignolo, "Cartas, crónicas y relaciones", op. cit.; Eduardo Viveiros de Castro, A inconstância da alma selvagem e outros ensaios de antropologia. 
estos autores y aquellos a los que Segundo sigue como historiador? Estas convergencias en disputa han hecho que el debate logre perfeccionar las dudas, sin que por necesidad se refinen las certezas sobre el encuentro y el efecto de la llegada de Occidente y su instalación en América. Y me atrevo a proponer el análisis de la obra de Segundo desde mi propia trinchera para comprender su empeño de "mirar como etnólogo".

Al parecer, antropólogos e historiadores se encuentran en la misma incertidumbre de los catecúmenos nahuas del siglo XvI: "Padre, no te espantes pues todavía estamos nepantla [...] que quiere decir estar en medio, entre una ley y otra". ${ }^{9}$ Mas, ¿eran los indios colonizados los únicos que estaban nepantla? ¿Los europeos fueron ajenos a esta incertidumbre, a pesar de lo que sus escrituras fundacionales expresaban? No es aventurado sostener que Segundo se halla inscrito en la clásica línea de reflexión historiográfica de Alfonso Mendiola y Guy Rozat, y así dedica mucha atención a la escritura de Hernán Cortés y, en su análisis, acierta en discernir genealogías discursivas distintas que ayudan a distinguir tinta empleada en las descripciones de la guerra militar y la del combate evangélico. Se sabe que las crónicas de la épica conquistadora no cesan de mostrar a esforzados y leales soldados de Dios y del Rey. A diferencia de los soldados que escriben crónicas, los frailes se enfrentan a un problema escriturístico distinto cuando pretenden tomar la palabra, capturando la memoria de los vencidos para mejor evangelizar. Y es de reconocer también que Segundo no olvida que Sahagún recoge informaciones de ancianos que vivieron la violenta metamorfosis de un mundo que, sin embargo, había sido erigido como un pasajero estadio previo a otras inevitables transformaciones futuras, en las cuales el parentesco y la cuenta del tiempo desempeñaban un papel crucial. Pero es necesario dar cuenta que considerar a Sahagún como un único referente de los textos sobre la evangelización es olvidar no

${ }^{9}$ Fray Diego Durán, Historia de las Indias de Nueva España, p. 196.

376 / Carlos Arturo Hernández Dávila 
sólo a otros autores, sino también el contexto en el cual el franciscano recogió sus materiales, luego de décadas de los sucesos que pretende ilustrar. Y aquí vale la pena atender las sugerencias, por ejemplo, de José Rabasa, quien había llamado la atención sobre cómo la obra de Sahagún no es uniforme en su producción, circulación y composición. ${ }^{10}$

¿Qué es exotizar, etnologizar las fuentes? Intentemos describirlo. Segundo nos recuerda que, en su Historia general de las cosas de la Nueva España, Sahagún relata que, a la llegada de Cortés ante el trono de Moctezuma, éste lo recibe diciéndole: "te has fatigado, te has dado cansancio: ya a la tierra tú has llegado. Has arribado a tu ciudad: México. Allí has venido a sentarte, en tu trono. Oh, por tiempo breve te lo reservaron, te lo conservaron, los que ya se fueron, tus sustitutos" (p. 21).

Esta escena hace decir a Segundo que "la entrega del reino es un símbolo de la incorporación, de la atracción al imaginario cristiano del retorno del Mesías”. ¿Pero no sería más sensato huir de este lugar común para escudriñar con más atención lo escrito en las crónicas, observando con más agudeza los símbolos inherentes en ellas? Segundo exhibe con detenimiento la genealogía discursiva de Occidente tanto en la guerra como en la conversión cristiana; pero ese mismo celo no se observa en analizar con detalle el trasvase desde la oralidad hasta la escritura en las obras de los frailes, por ejemplo. De hacerlo, podría ayudarle a descubrir senderos aún más fascinantes. Por caso: lo que en América era una suerte de destino inevitable (la posibilidad de transformarse en "otros"), en Europa se vivió como una batalla imposible de perder: era menester mantenerse como un "nosotros" fiel e inconmovible, defendiendo la identidad corporativa a toda costa. El antropólogo James Clifford, indagando sobre los modos en cómo se escriben las historias del contacto, dice de éstas que

${ }^{10}$ José Rabasa, "Ecografías de la voz en la historiografía nahua”. 
han sido estructuradas por una penetrante dicotomía: absorción por el otro o resistencia ante el otro. Pero ¿qué pasa si la identidad se concibe no como un límite a ser mantenido sino como un nexo de relaciones y transacciones que comprometen activamente a un sujeto? La historia o las historias de la interacción deben ser, entonces, más complejas, menos lineales y teleológicas. ¿Qué cambia cuando el sujeto de la "historia” ya no es occidental? ¿Cómo se presentan las historias de contacto, resistencia y asimilación desde el punto de vista de grupos en los que el intercambio, antes que la identidad, es el valor fundamental a sostener? ${ }^{11}$

Los pueblos amerindios son sociedades del intercambio en su sentido más amplio. Es así que Moctezuma no sólo entrega el trono y el poder a Cortés, sino que sin ambages lo declara pariente, ancestro, consanguíneo, sucesor. Mediante esta operación, Cortés es colocado en una dilatada genealogía mediante una operación que no es distinta a lo que declaraban los indios guañonas de Surinam o los guaraníes del Paraguay, cuando afirmaban sin reservas que descendían de dos hermanos que habían llegado desde España. ${ }^{12}$ Miguel Segundo insiste en proseguir el "trabajo sobre el mito" (a la manera de Hans Blumenberg), ${ }^{13}$ apostando por una lectura de las crónicas militares y religiosas del siglo XVI en la Nueva Espańa y provisto de esta poderosa prótesis analítica. Pero además de ser fuentes históricas, los textos pueden ser llevados al nivel de datos etnográficos que hablan mucho del sujeto descrito pero que dicen a veces mucho más del descriptor y el mundo de signos y representaciones que lo animan.

Sostengo que etnografiar las fuentes es una tarea radicalmente posible: examinando las crónicas de jesuitas de la evangelización

${ }^{11}$ James Clifford, The Predicament of the Culture: Twentieth Century Ethnography, Literature and Art, p. 401.

${ }^{12}$ Guillermo Wilde, Religión y poder en las misiones guaranies, pp. 125-126.

${ }^{13}$ Hans Blumenberg, Trabajo sobre el mito.

378 / Carlos Arturo Hernández Dávila 
temprana del Brasil, Eduardo Viveiros de Castro somete a escrutinio el alma ignaciana a través de las descripciones que los padres hacen a su vez del alma indígena en un verdadero juego de espejos. Los indios del Brasil no mantenían un sistema religioso tan sofisticado como el de los nahuas del altiplano central de México, y aparecían como inmóviles y pacíficos mirtos a quienes el misionero-jardinero podía dar la forma deseada sin que opusieran la menor resistencia. "Desean en todo ser como nosotros", dicen los jesuitas. ${ }^{14}$ En la Nueva España, los primeros evangelizadores contaban por millones los bautizados y conversos, "niños de blanda cera, dóciles y entregados al servicio del único dios Verdadero". ${ }^{15}$ Los jesuitas en Brasil muy pronto caen en el desaliento ante estos arrayanes sumisos pero endebles: "Eran como su tierra, engañosamente fértil, dónde parecía que todo se podía plantar, pero donde nada brotaba que no fuera sofocado de inmediato por la mala hierba. Esas gentes sin fe, sin ley y sin rey, no ofrecían un suelo psicológico o institucional donde el Evangelio pudiese echar raíces" ${ }^{16}$

Pero en México, el más agudo testigo del desengaño que sobreviene a la primera y enclenque evangelización es precisamente fray Bernardino de Sahagún, justo gracias a la distancia que media entre la primera evangelización y los tiempos que él describe. El problema de Segundo es que "su" Sahagún es sólo el que escribe la Historia general de las cosas de la Nueva España. Sahagún va más allá: vio otras cosas, escuchó y consignó diferentes elementos, e incluso es capaz de mirarse y describirse a si mismo y a sus hermanos frailes. Por ejemplo, con la frustración como tinta, escribe:

No se olvidaron [los primeros evangelizadores] en su predicación, del aviso que el Redemptor encomendó a sus discípulos y apóstoles cuando les dijo: estote prudentes sicut serpentes et sim-

\footnotetext{
${ }^{14}$ Eduardo Viveiros de Castro, "O mármore e a murta: sobre a inconstância da alma selvagem", p. 202.

${ }^{15}$ John L. Phelan, El reino milenario de los franciscanos en el Nuevo Mundo, p. 12. ${ }^{16}$ Ibidem, p. 186.
} 
plices sicut culumbae: sed prudentes como serpientes y simples como palomas. Y aunque procedieron con recato en lo segundo, en lo primero faltaron, y aun los mismos idólatras cayeron en que les faltaba algo de aquella prudencia serpentina y así, con su humildad vulpina, se ofrecieron muy prontos al recebimiento de la fe que se les predicaba. Pero quedáronse solapados en que no detestaron ni renunciaron a todos sus dioses con toda su cultura, y así fueron baptizados no como perfectos creyentes, como ellos mostraban, sino como fictos, que recibían aquella fe sin dejar la falsa que tenían de muchos dioses. Esta paliación no se entendió a los principios, y la causa potísima de ella fue la opinión que los dichos predicadores tomaron de su perfecta fe, y así lo afirmaron a todos los ministros del Evangelio que sobrevinieron a predicar a esta gente [...] A todos nos fue dicho (como ya se había dicho a los padres dominicos) que esta gente había venido a la fe tan de veras, y estaban casi todos baptizados y tan enteros en la fe católica de la Iglesia Romana, que no había necesidad alguna de predicar contra la idolatría, porque la tenían dejada ellos muy de veras. Tuvimos esta información por muy verdadera y milagrosa, porque en tan poco tiempo y con tan poca lengua y predicación, y sin milagro alguno, tanta muchedumbre de gente que se había convertido ${ }^{17}$

El fraile-cronista comprende que mucho de lo hecho y dicho hasta esos años no fue tan útil como se pensaba, siendo necesario conocer mejor y desde dentro el anverso y reverso de las palabras e intenciones más secretas de los indios, quienes por otra parte se asumían como cristianos sinceros, si bien en el ya aludido "modo nepantla", característica que como la etnografía lo confirma, se mantiene vigente hasta el sol de hoy. ${ }^{18}$ El juego de la alteridad constituyente brota con necedad casi a casa página de muchas

\footnotetext{
${ }^{17}$ Bernardino de Sahagún apud Joaquin García Icazbalceta, Bibliografía Mexicana del siglo XVI, p. 382-383.

${ }^{18}$ Saúl Millán, "La alteridad permanente: cosmovisiones indígenas, teorías antropológicas".
} 
crónicas: por ejemplo, el cronista indígena tlaxcalteca Diego Muñoz Camargo anotaba: "Y finalmente sobre este argumento sobre si [los españoles] eran dioses ú hombres no se sabía determinar, porque si ellos fuesen dioses, decían ellos, no derribaran a nuestros oráculos, ni maltrataran a nuestros dioses, porque fueran sus hermanos, y pues que los maltratan y derriban no deben de ser dioses, sino gentes bestiales y bárbaras". ${ }^{19}$

De nuevo el código de observancia al parentesco consanguíneo aparece en primer plano para cuestionar las fallas en la incorporación, demostrada por medio de la bestial violencia hispánica. La extrañeza es mutua. Insólita. Desequilibrante. Lévi-Strauss llama la atención sobre cómo, mientras los españoles trataban de averiguar si los indios estaban dotados de alma, los indios enfocaban su indagación en descubrir si el cuerpo de los españoles era homólogo al suyo. ${ }^{20}$ En lo que toca al problema de la conversión, Segundo apuesta por demostrar la necesidad franciscana de crear memorias nuevas que den fondo a la tarea evangelizadora: para ello es preciso inventar las categorías de "pecado" (tlatlacolli) y el de "pecar" (itlacoa) como máquinas de guerra contra una sociedad que habita cuerpos entregados al deleite. Miguel Segundo devela la ficción, la invención del indio penitente y enemigo del placer de la carne, así reelaborado en la escritura frailesca, listo para recibir el evangelio. Sahagún hace decir a sus informantes que "Los antiguos mexicas eran penitentes (tlamacehualliztli), se humillaron y anduvieron encorvados e inclinados hacia la tierra, con lloros lágrimas y suspiros, no se estimaron como señores sino como pobres y peregrinos" (p. 232). Tal es la quimera del fraile, pero cabe preguntarse cómo veían, sin filtro, los indios a los hijos del poverello de Asís. Sabemos que los principales de Tlaxcala se asombran del poco afecto a la vida (al deleite, al bien-estar-en el mundo) de los hijos de san Francisco. Decían los pipiltin (nobles) que

\footnotetext{
${ }^{19}$ Diego Muñoz Camargo, Historia de Tlaxcala, p. 165.

${ }^{20}$ Claude Lévi-Strauss, "Race et histoire”, p. 384.
} 
Estos pobres [los frailes] deben de ser enfermos o estar locos, dejadlos vocear a los miserables; tomándoles ha su mal de locura; dejadles estar, que pasen su enfermedad como pudieren. No les hagáis mal, que al cabo éstos y los demás han de morir de esta enfermedad de locura. Y mirad, si habéis notado, cómo a mediodía, a medianoche y al cuarto del alba, cuando todos se regocijan, éstos dan voces y lloran. Sin duda ninguna es mal grande el que deben de tener porque son hombres sin sentido, pues no buscan placer ni contento sino tristeza y soledad. ${ }^{21}$

Ambas perspectivas se entrecruzan sin tocarse, y hay un empeño por hacer de los indios una suerte de frailes laicos. Segundo sostiene que

Es un discurso conservador, sin duda ¿pero de qué valores? ¿Los prehispánicos o los formados en el convento? Con la escritura se aspira a recobrar las viejas costumbres. En el ejercicio retórico, basado en la moral de los antepasados prehispánicos, ¿se encuentra una verdad indígena mesoamericana? El hecho de que se presente en náhuatl no implica que el horizonte de inteligibilidad sólo se pueda encontrar en el menosprecio del mundo cristiano. ¿De quién era el miedo al mundo? ¿De los mexicas o de los frailes? Es una verdad universal: El mundo es un tránsito, en donde se viene a sufrir, en medio de un valle de lágrimas, aun en los tristes trópicos mexicas (p. 227).

La percepción del mundo como tránsito, como sitio por ser continuamente interpretado, es sin duda una generalización atractiva. Estas figuras retóricas empujan a Segundo a insistir en la certeza de que las Crónicas surgieron "como una nueva memoria que fuera capaz de darle sentido al mundo que nacía, como la institución y el anclaje para pensar el futuro de esa sociedad. Un pasado fundacional para el Nuevo Mundo" (p. 410). Acaso

${ }^{21}$ Muñoz Camargo, Historia de Tlaxcala, op. cit., pp. 174-175.

382 / Carlos Arturo Hernández Dávila 
por esto es que su libro debe leerse más como un manual de viaje que no reclama el seguimiento de un horizonte cronológico, sino que apela al discernimiento de diversas epistemes que trazan la ruta de sus argumentos, pues Segundo logra que en sus páginas se sientan cómodos lo mismo Hesíodo que Joaquín de Fiore, Flavio Josefo junto con Agustín de Hipona, Tomás de Aquino e Irineo de Lyon.

Revisando la obra en su conjunto, es imposible no reconocer el aporte del autor a la hora de entender cómo la imaginería occidental, su horizonte visual y su potencial figurativo, simbólico y persuasivo, fue trasladado de modo íntegro a tierras americanas como si de refuerzos militares se tratara, para acelerar la narración, delimitación, traducción e interpretación que diera cuenta de tierras, mares y ríos poblados por seres no previstos ni en la cosmología europea, ni mucho menos en sus modelos epistémicos, y acaso tal vez mencionado en algunas revelaciones de orden místico.

Empecé este comentario crítico reconociendo que la obra de Segundo se inscribe en una línea de reflexión ya muy acreditada, gracias al trabajo de los autores que la han nutrido. Evocando a Guy Rozat, la escritura sobre esta América y sus vicisitudes sigue siendo un "Imperio del demonio", un eterno significante en busca de significados. El debate, con ventura, se ha extendido a otros campos del quehacer tanto histórico como etnológico. Y si Segundo confirma que la lógica devastadora de Occidente se hace acto (se vuelve factible) cuando "el otro debe ser transformado, desde una mirada etnocida se busca la mismidad: el interés por alteridad sólo existe para su conversión” (p. 409), es gracias a afirmaciones como ésta como puedo sostener que, a pesar de observar la obra desde una orilla metodológica distinta, la etnologización de las fuentes que persigue es asimismo, factible.

Carlo Ginzburg escribió un emotivo texto llamado "Lo que aprendí de los antropólogos”. Como etnólogo sostengo que el título de este comentario crítico debería reescribirse y titularse simplemente "Lo que aprendí de(l debate entre) los historiadores". 些 


\section{BiBLIOGRAFÍA}

Baudot, Georges. La pugna franciscana por México, México, Conaculta, 1990.

Bartra, Roger. El salvaje artificial, México, Fondo de Cultura Económica/ Ediciones Era, 1997.

- El salvaje en el espejo, México, Fondo de Cultura Económica/ Ediciones Era, 1992.

Bernard, Carmen. "Los nuevos cuerpos mestizos de la América Colonial", en Manuel Gutiérrez Estévez y Pedro Pitarch (coords.), Retóricas del cuerpo amerindio", Madrid, Iberoamericana Vervuert, pp. 89-111.

Burkhart, Louise M. The Slippery Earth: Nahua-Christian Moral Dialogue in Sixteenth-Century Mexico, Tucson, University of Arizona Press, 1989.

Clifford, James. The Predicament of the Culture: Twentieth Century Ethnography, Literature and Art, Cambridge \& London, Harvard University Press, 1988.

Diaz Balsera, Viviana. The Pyramid under the Cross. Franciscan Discourses of Evangelization and Christian Nahua Subjet in the Sixteenth-Century México, Tucson, University of Arizona Press, 2005.

Durán, Diego, Historia de las Indias de Nueva España, t. I, cap. viI, México, Porrúa, 1984.

García Icazbalceta, Joaquín. Bibliografía mexicana del siglo XVI. Catálogo razonado de libros impresos en México de 1539 a 1600, con biografías de autores y otras ilustraciones. Precedido de una noticia acerca de la introducción de la imprenta en México, ed. de Agustín Millares Carlo, México, Fondo de Cultura Económica, 1954.

González, Luis. Jerónimo de Mendieta. Vida, pasión y mensaje de un indigenista apocalíptico, Zamora, El Colegio de Michoacán, 1990.

Hernández Dávila, Carlos Arturo. "Cuerpos de Cristo. Cristianismo, predación y conversión en la sierra de las Cruces y Montealto, Estado de México”, tesis de Doctorado, México, ENAH, 2016.

Lévi-Strauss, Claude. Historias de Lince, Barcelona, Anagrama, 1999.

-. "Race et histoire", en Anthropologie structural deux, París, Plon, 1958.

López Meraz, Óscar Fernando. "Memoria, experiencia y cuerpo en crónicas franciscanas del siglo xvi: la construcción del natural mesoamericano", Historia y Grafía, núm. 54 (27), enero-junio 2020, pp. 13-52. Dispo-

384 / Carlos Arturo Hernández Dávila 
nible en: <https://www.revistahistoriaygrafia.com.mx/index.php/HyG/ article/view/296>.

Madrigal, Luis Ínigo. Historia de la literatura hispanoamericana, vol. 1, Madrid, Cátedra, 1993.

Mendieta, fray Jerónimo de. Historia eclesiástica indiana, México, Conaculta, 1997.

Mendiola, Alfonso. "El giro historiográfico. La observación de observaciones del pasado", Historia y Grafía, núm. 8, 2000, núm. 15, pp. 181-208. . Retórica, comunicación y realidad. La construcción retórica de las batallas en las crónicas de conquista, México, Universidad Iberoamericana, 2003.

Mignolo, Walter. "Cartas, crónicas y relaciones del descubrimiento y la conquista”, en Luis Ínigo Madrigal, Historia de la literatura hispanoamericana, vol. 1, Madrid, Cátedra, 1993, pp. 57-116.

. The Darker Side of the Renaissance. Literacy, Territoriality, \& Colonization, Michigan, University of Michigan Press, 1995.

Millán, Saúl. "La alteridad permanente: cosmovisiones indígenas, teorías antropológicas", Scriptha Ethnologica, vol. xxxviI, 2015, pp. 82-100.

Muñoz Camargo, Diego. Historia de Tlaxcala, publicada y anotada por Alfredo Chavero, México, Secretaría de Fomento, 1892.

Phelan, John L. El reino milenario de los franciscanos en el Nuevo Mundo, México, tr. de Josefina Vázquez de Knauth, México, unam-Instituto de liwestigaciones Históricas, 1972.

Rabasa, José. "Ecografías de la voz en la historiografía nahua", Historia y Grafía, núm. 25, 2005, pp. 101-151.

Rozat Dupeyron, Guy. América, Imperio del demonio. Cuentos y recuentos, México, Universidad Iberoamericana, 1995.

. "Los relatos de la conquista de México como hoyo negro de una memoria esquizofrenizante", Historia y Grafía, núm. 47, julio-diciembre 2016, pp. 17-48. Disponible en: <https://www.revistahistoriaygrafia.com.mx/index.php/HyG/article/view/146>.

Suárez Gómez, Ainhoa. “Historiología: Edmundo O’Gorman, José Ortega y Gasset, y los fundamentos de la ciencia de la historia”, Historia y Grafía, núm. 54, enero-junio 2020, pp. 231-297. Disponible en: <https:// www.revistahistoriaygrafia.com.mx/index.php/HyG/article/view/292>.

Segundo, Miguel. Historia y mirada de las crónicas de América, Universidad de Guanajuato, 2018. 
Todorov, Tzvetan. La conquista de América. El problema del otro, México, Siglo xxi Editores, 2007.

Viveiros de Castro, Eduardo. "Multinaturalismo y perspectivismo en la América Indígena”, en Alexandre Surrallés y Pedro García Hierro (eds.), Tierra adentro. Territorio indígenas y percepción del entorno, Lima/Copenhague, IWGIA, 2004, pp. 37-85.

__. "O mármore e a murta: sobre a inconstância da alma selvagem", en $A$ inconstância da alma selvagem e outros ensaios de antropologia, São Paulo, Cosacnaify, 2002, pp. 186-263.

Wilde, Guillermo. Religión y poder en la misiones guaranies, Buenos Aires, sв Editorial, 2016. 